\title{
A year of engaging with the discipline of noticing: five mathematics lecturers' reflections
}

\author{
Sinead Breen ${ }^{\mathrm{a}}$, Aisling McCluskey ${ }^{\mathrm{b}}$, Maria Meehan ${ }^{\mathrm{c} *}$, Julie O’Donovan ${ }^{\mathrm{d}}$ and \\ Ann O'Shea ${ }^{\mathrm{e}}$ \\ ${ }^{a}$ Mathematics Department, St Patrick's College, Dublin, Ireland; ${ }^{b}$ School of Mathematics, Statistics \\ and Applied Mathematics, National University of Ireland, Galway, Ireland; 'School of \\ Mathematical Sciences, University College Dublin, Dublin, Ireland; ${ }^{d}$ Mathematics Department, \\ Cork Institute of Technology, Cork, Ireland; ${ }^{e}$ Department of Mathematics and Statistics, \\ National University of Ireland, Maynooth, Ireland
}

(Received 22 January 2013; final version received 11 September 2013)

\begin{abstract}
In September 2010, five mathematics lecturers set out on a professional development project with the following aim: to reflect on teaching practice using John Mason's Discipline of Noticing. At the end of the academic year, each lecturer considered her experiences of engaging with the process. In this paper, we describe the observations made and discuss the benefits and challenges of engaging with the Discipline of Noticing, namely, the benefits of a collaborative approach; the challenges of 'noticing in the moment' and the advantages of and difficulties with, writing brief-but-vivid accounts.
\end{abstract}

Keywords: reflection; discipline of noticing; brief-but-vivid accounts

\section{Introduction}

The five authors of this paper are mathematics lecturers from five university-level institutions in Ireland who embarked on a professional development project with the aim of developing sustained reflection on, and critique of, their teaching practice using John Mason's (2002) Discipline of Noticing. It was decided that for the academic year 2010 2011, each lecturer would keep accounts of moments or critical incidents from her teaching and periodically circulate these to the rest of the group. It transpired at the group meetings, held every six to eight weeks, that there was discussion about the Discipline of Noticing itself and due to the predominance of these discussions, each lecturer reflected on her experiences of engaging with the process at the end of the academic year. In this paper, we describe these experiences and address the following research question: what are the benefits and challenges for third-level mathematics lecturers of engaging with the Discipline of Noticing as a means of reflection?

The value of reflection for teachers at all levels has been widely acknowledged (Bell, Mladenovic, and Segara 2010; National Council of Teachers of Mathematics [NCTM] 2010). The literature on reflection is extensive, with multiple meanings attached to the term, and references to the concept appearing in a wide range of disciplines (Hatton and Smith 1995; Moon 2004). While a discussion of reflection can be found in Dewey's

\footnotetext{
${ }^{*}$ Corresponding author. Email: maria.meehan@ucd.ie 
Democracy and Education published in 1916, most of the literature on the topic dates from 1980s onwards with Schön's $(1983,1987)$ work on the role of reflection-in-practice and reflection-on-practice within a variety of professions acting as a catalyst for study in this area.

In this paper, we report on our experience of using a particular form of reflection, that is Mason's Discipline of Noticing. We will describe the Discipline of Noticing in detail in the next section, but Mason $(2002,59)$ summarises it as 'a collection of practices which together can enhance sensitivity to notice opportunities to act freshly in the future'. When considering Mason's work, Loughran $(2006,46)$ spoke of the close relationship between noticing and reflection:

A most important issue that he [Mason] raises relates to the point that if something is not noticed, then it is unlikely that a response will be forthcoming. Therefore that which is noticed, how and why, carries influence not only on the nature of reflection but also on the action(s) as a result of reflection.

He also observed that the purpose of reflection could influence that which is noticed, and so noticing and reflection are closely linked.

Researchers have used the term noticing in ways that are slightly different to Mason's. For example, van Es and Sherin $(2002,573)$ defined the aspects of noticing as follows:

(a) identifying what is important or noteworthy about a classroom situation; (b) making connections between the specifics of classroom interactions and the broader principles of teaching and learning that they represent and (c) using what one knows about the context to reason about classroom events.

Some authors may consider noticing as a process which only involves aspect (a) above, but Sherin, Jacobs, and Philipp $(2011,5)$ reported that for most researchers in this field noticing involves both attending to and making sense of events in a classroom situation. They advocate the use of noticing by teachers and assert that it can lead to adaptive and responsive teaching, can allow teachers to learn from teaching (for example, by attending to students' thinking), and can help them decompose practice into core activities and develop a language with which these can more readily be discussed.

There have been relatively few studies that involve mathematicians at university level making use of noticing in their classrooms or reflecting on their own teaching. Indeed, Speer, Smith III, and Horvath (2010) considered undergraduate mathematics teaching and noted that

very little research has focused directly on teaching practice - what teachers do and think daily, in class and out, as they perform their teaching work. (99)

However, some work has been done on this topic recently, for example, by McAlpine and Weston (2000), Paterson, Thomas, and Taylor (2011), Hannah, Stewart, and Thomas (2011) and Jaworski and Matthews (2011). These studies employed a variety of different conceptualisations of reflection but have at least two features in common - first, reflection is undertaken as a collective endeavour, and second, both mathematicians and mathematics educators are involved in the process. 


\section{The discipline of noticing}

Mason (2011, 37-38) characterises the Discipline of Noticing as follows:

The discipline of noticing is a collection of techniques for (a) pre-paring to notice in the moment, that is, to have to come to mind appropriately and (b) post-paring by reflecting on the recent past to select what you want to notice or be sensitised to particularly, in order to pare, that is, to notice in the moment. (Italics author's own)

In Mason (2002, 33-34), he distinguishes between three levels of noticing: 'ordinarynoticing' in which one's memory of something can be jogged if someone else remarks upon it; 'marking' in which one has taken sufficient notice of something to 'remark' upon it to someone else and 'recording' where one makes a note of something one has noticed, usually in writing. He proposes that each level of noticing requires an additional level of energy in order to enact it. However, he suggests that energy is often dissipated when we grumble about an incident to others, and this energy could be put to better use in recording the incident. To do this, he specifically advocates the writing of 'brief-butvivid' (46) accounts. These are brief accounts which give an 'account-of' a situation or incident, rather than an 'account-for' it. Mason (41) explains:

To account-for something is to offer interpretation, explanation, value-judgement, justification or criticism. To give an account-of is to describe or define something in terms that others who were present (or who might have been present) can recognise.

A reason for giving an account-of, as opposed to an account-for, is to force 'an inner split between actor and observer' (19), allowing one to reenter the experience perhaps more objectively at a later stage, without biasing the account with personal views at the time of writing. An account should be vivid in the sense that someone who reads it can recognise or recollect a similar situation or phenomenon from his or her own experiences. In particular, he stresses that brief-but-vivid accounts are not the data for professional development: 'They are merely entry points to experience. It is the experience which is the data' (52).

Mason $(2002,95)$ summarises the collection of practices involved in noticing using four headings: systematic reflection, recognising, preparing and noticing, and validating with others. 'Systematic reflection' involves not only keeping brief-but-vivid accounts but also examining a collection of accounts to find 'threads' (65) or themes that perhaps highlight, or sensitise you to, some aspects of your practice. Working on accounts with others can lead to phenomena being identified and labelled (79) as well as alternative strategies being distinguished. Mason asserts that this process increases the likelihood of recognition both of choices and of possibilities for acting differently in the future (70). This is what he describes as 'recognising'. To increase the chances of noticing a possibility during a class and having an alternative technique come to mind in-themoment, Mason advocates vividly imagining oneself carrying out the technique. He refers to this step in the process as 'preparing and noticing'. Finally, an important action of the Discipline of Noticing is highlighted as the 'construction, refinement and modification of means to communicate and enrich noticing with others' (90). This can be achieved via a 'task-exercise' (91), which is an account that has been refined or honed from a brief-but-vivid account or accounts to produce a description of something that 
others can instantly recognise and identify with. This is what he describes as 'validating with others'.

The individual hoping to engage in 'disciplined rather than sporadic and serendipitous noticing' (Mason 2002, 61) must be prepared to work on the collection of practices described above in a manner that is 'systematic and methodical without being mechanical' (59). One must discipline oneself to engage in, and develop, these practices over a sustained period of time, and it is, therefore, not surprising that Mason states that the 'Discipline of Noticing is aimed at individuals working within a group' (144). He goes further to say that if the aim of the individual is to experience real change in practice:

it is almost impossible to achieve without a supportive community which develops a shared language, helps maintain focus and enable individuals to compare and share experiences, hopes and struggles, so that there is transformation of the social as well. (144)

To summarise, as a professional development tool, the Discipline of Noticing provides us with a collection of practices that we can engage in, preferably in a group setting, to enable us to become more sensitive to aspects of our practice that we may wish to change; to enable us to develop the sensitivity to recognise opportunities to act freshly as they arise and to prepare us to have alternative options come to mind as the need arises.

\section{Methodology}

The five lecturers involved in this project have Ph.D.s in either Pure Mathematics or Applied Mathematics. While all have engaged in mathematics research, most have also recently engaged in mathematics education research. Four of the five have over 12 years' experience of teaching mathematics at third-level, while the fifth has been lecturing for eight years. Most have taught a range of modules from first year to masters' level and have taught classes ranging in size from single figures up to approximately 300 students.

The 'Noticing Group' first met in September 2010 and decided that for the academic year 2010-2011, they would bring their teaching and research into closer relationship by each writing brief-but-vivid accounts of moments or incidents from her lectures that would be circulated to the other members of the group regularly for discussion and later analysis. One lecturer took responsibility for setting deadlines for the accounts to be circulated and for the coordination of the group meetings. The number of accounts submitted varied from lecturer to lecturer with some writing an account-of an incident from almost every lecture, while others wrote accounts more sporadically. The lecturers involved were teaching a range of modules from a first-year mathematics module for Civil Engineers to a masters' level course in Analytic Topology. It was also decided that the group meet every six to eight weeks to discuss any matters relating to the project. In all, there were five circulations of accounts and five meetings between September and May. Topics discussed during meetings varied. Sometimes, there were discussions around a particular account, sometimes, there were similarities drawn between individuals' accounts, and often the discussion digressed into some area of mathematics education or some issue concerning classroom practice or student understanding. At every meeting, there was a discussion on engaging with the Discipline of Noticing.

Due to the predominance of the discussions on the Discipline of Noticing, it was decided that each lecturer would write her reflections on the process of engaging with the 
discipline for the academic year 2010-2011 and circulate these to the group. To ensure that each individual's reflections would be independent of the others, the group members agreed not to read any other reflections prior to writing her own. No other criteria were agreed for either the format or the content of these reflective pieces. It is these reflections that we wish to present and discuss in this paper with a view to addressing our research question: What are the benefits and challenges for third-level mathematics lecturers of engaging with the Discipline of Noticing as a process of reflection?

The reflections submitted by each lecturer were between 500 and 1200 words in length. Two of the authors independently coded all five sets of reflections, using grounded theory (Strauss and Corbin 1998). In reading each reflection, they coded (or labelled) the points made. When they came across a similar point made by another person, they used the same code as before or modified the original code so that it would more appropriately describe all the comments it labelled. Having done this they grouped the codes into categories with one author, using five major categories while the other used four. However, despite some minor differences in the selection and naming of a few of the categories (one author had used two categories where the other had used one), both authors' codings were very similar. There was agreement on these codes within the group, and in the next section, we present these results. (A brief summary of these results can be found in Breen et al. (2011).)

\section{Results}

Despite being written independently, all five lecturers reflected on most of the following themes to a greater or lesser extent:

- Benefits of collaboration

- Challenges of writing brief-but-vivid accounts

- Benefits of writing brief-but-vivid accounts

- Challenges of noticing in-the-moment

In this section, we describe the lecturers' reflections under each heading, referring to the lecturers as Lecturers A, B, C, D and E. These names have been randomly assigned.

\section{Benefits of collaboration}

All five lecturers were united in stating the importance of undertaking the reflection project as a group. First, working as part of a group provided the necessary motivation and discipline to keep writing accounts throughout the year. This was the main practice that all five lecturers engaged with, and the deadlines for accounts to be circulated meant that the project remained in the forefront of everyone's mind.

Personally, I am quite certain nothing would have happened at an individual level without the group level. There was a 'healthy guilt' to have accounts sent in around the deadline. (Lecturer A)

Working as part of a group also provided the motivation to continue making the effort to write accounts that were brief-but-vivid. 
certain that over time, my accounts would have just become logs of the material I covered in each lecture. (Lecturer B)

Mason $(2002,61)$ might describe this as being 'methodical without being mechanical'.

Second, the benefits of meeting up as a group were highlighted. These include the benefits of discussing one's classroom practice with others, learning from what others are doing in practice, clarifying aspects of the Discipline of Noticing with others, and motivating and supporting engagement in the project.

Regular meetings provided motivation and encouragement. The meetings provided a forum for discussions of the accounts. I found it very helpful to be able to discuss and relate similar experiences within the classroom and to listen to others articulate situations I could relate to. I always left meetings feeling better informed and enthused about continuing on this project. (Lecturer A)

Third, working as a group means that each member has access to the accounts of the other group members. These also provide windows into the ways others deal with situations in the classroom and think about their teaching. Therefore, it is not surprising that reading the accounts circulated was described by some of the lecturers as being an interesting and important component of the project.

I found reading other people's accounts really interesting. I liked finding out about different teaching styles and hearing how others dealt with problems. I think that this is a real benefit of a project like this. (Lecturer D)

In addition to providing insights into the practice of others, at least some of the accounts circulated provided 'good' examples of brief-but-vivid accounts. In attempting to master the art of giving an account-of rather than an account-for an incident, it was useful to analyse others' accounts for these qualities. One lecturer who was questioning how worthwhile providing an account-of an incident was, found that reading the accounts of others helped her see the benefits of such an approach.

Thus I have struggled with reporting on noticed moments in an 'account-of' manner. I have noticed however that through time and particularly with the benefit of sharing accounts with the rest of the group that it is entirely possible to report usefully and meaningfully in such a manner. (Lecturer C)

\section{Challenges of writing brief-but-vivid accounts}

Not surprisingly, all of the lecturers reflected on the process of writing brief-but-vivid accounts and on the challenges involved. As one might expect, one of the first challenges encountered was that of actually having the discipline to write accounts (although the group dynamic helped). Most of the lecturers specifically set themselves the goal of writing an account after each lecture, choosing to focus on a specific event or incident from the lecture. However, sometimes they found it difficult to find the time, or simply forgot. Interestingly, in relation to actually writing the accounts, two of the lecturers commented on the fact that because the account had to be brief and vivid, and/or provide an account-of an incident rather than an account-for, they (initially at least!) felt the task should be a straightforward one. 
I found the idea of 'noticing rather than defending, explaining and justifying' helpful in initiating the report writing in that, all I was required to write down was what happened and not an indepth analysis. [...] However, ironically I think I gave a considerable amount of personal interpretation in the account and found it rather difficult to state just what happened without any personal commentary. (Lecturer A)

Lecturer B reported feeling that the task of writing a brief-but-vivid account seemed 'much less daunting' than that of writing a more reflective piece. Another challenge arising related to the decision on what to write about, and Lecturer D observed that sometimes it seemed like there was nothing of note to write about or that a particular incident which she had already written an account-of, kept reoccurring.

Perhaps the two biggest challenges experienced by the lecturers in relation to briefbut-vivid accounts, were the challenge of writing an account-of, as opposed to an account-for, an incident; and the challenge of achieving the appropriate levels of brevity and vividness. The comment above by Lecturer A highlights the difficulty she experienced in writing an account-of an incident as opposed to an account-for. She was not alone in this regard, and Lecturers D and E echoed her comments. The challenge of achieving brevity and vividness was experienced differently by members of the group. Lecturer E struggled with getting the balance right between brief and vivid and even at the end of the year admitted that she 'found, and still finds, the notion of a brief-but-vivid account difficult to grasp'. Lecturer D and Lecturer B were at opposite ends of the spectrum when describing the challenges each experienced, with Lecturer D describing how she felt she was able to write brief-but-not-so-vivid accounts, while Lecturer B reflected on how she struggled to tone down the vividness and had to spend significant time and effort refining her accounts.

I found it easy enough to write brief accounts but hard to write vivid ones. When I read my accounts now, I remember the experience that I was trying to capture but I realise that it would be difficult for other people to know what that experience really was. (Lecturer D)

My first attempt at an account is usually passionate and long and all over the place, but I find that over several edits it seems to converge to something that isn't exactly a brief-but-vivid account by Mason's standards, but is my attempt at a compromise account. (Lecturer B)

Finally, we discuss a fifth challenge that some of the group experienced in writing briefbut-vivid accounts: how to write about emotion in accounts. At each group meeting, there was considerable debate over whether emotion was 'allowed' in an account, and if it was, how it should be described. The appearance of the words 'restrain' and 'passionate' in Lecturer's B reflection above alludes to her struggle to tone down the emotion in her accounts, Lecturer E wrote about writing accounts 'without emotion' and Lecturer C also noted significant difficulty in this regard. These lecturers seem to have a particular sense of what a brief-but-vivid account should look like and may be misinterpreting what Mason says.

\section{Benefits of writing brief-but-vivid accounts}

Despite the challenges faced in writing brief-but-vivid accounts, the benefits of persisting in the process were articulated by most of the group. As noted earlier, one of the reasons why Mason $(2002,19)$ advocates giving an account-of an incident, as opposed to an 
account-for, is to force 'an inner split between actor and observer'. He also suggests that when frustrated by something that has happened, rather than complain about it, one should write an account. Lecturer B and Lecturer E wrote about both of these benefits in their reflections.

... by writing my whinges down as (bland) accounts instead of just spoofing off, it somehow enabled me to gain a bit more perspective. Often I found myself thinking more about where the student might be coming from, and questioning whether what I was expecting was unreasonable. It helped me stand back and view incidents in a more measured way. (Lecturer B)

I did find that persisting in trying to write an 'account-of' an incident, without emotion or justification, did help me appreciate the students' perspective more, rather than resorting to self-justification. (Lecturer E)

Perhaps most significantly of all, three of the lecturers reflected on what was emerging for them from their collections of accounts and had become aware of issues which needed further investigation and thought:

In previous years, issues that concerned me may have hung around vaguely in the air and were nothing more than feelings, but by writing the accounts, they have become more tangible and better articulated. Because of this I now feel I am in a better position to constructively deal with them. (Lecturer B)

I hoped that the process would help me improve my teaching. I think it certainly helped me to stand back from it a little and try to analyse it. ... I feel that it has made me aware of some issues but now I need to think about how to change what I do. This is the hard part. (Lecturer D)

Over the year, I found the same type of critical incident coming to mind a number of times indicating, perhaps, an issue I needed to address or had not successfully addressed. (Lecturer E)

Lecturer E noted an additional benefit of keeping accounts. Her research interests are in mathematics education, and as a teacher, she frequently attempts to incorporate certain tasks to support student learning into her classes. She found that reading her brief-butvivid accounts enabled her to evaluate these tasks more objectively. She also observed how her knowledge of the mathematics education literature influenced her reading of her accounts.

In trying to identify a critical incident and then focusing on it in order to verbalise it, I found that I could sometimes relate what was happening to phenomena/constructs described in the literature. (Lecturer E)

\section{Challenges of noticing in-the-moment}

As noted previously, Mason $(2002,59)$ describes the Discipline of Noticing as 'a collection of practices which together can enhance sensitivity to notice opportunities to act freshly in the future'. We were interested in whether engaging in the practice of 
keeping brief-but-vivid accounts had increased the participants' sensitivity to notice such opportunities. Four of the lecturers addressed the idea of noticing 'in-the-moment' in their reflections. Three reported little success, especially during the first semester. Lecturer C, in particular, felt that noticing in-the-moment and enjoying the flow of the lecture were mutually exclusive.

For me there was an uneasy tension in trying to enable and then enjoy the flow of a class against trying to notice various features alongside this. (Lecturer $\mathrm{C}$ )

Moreover, Lecturer B reflected that it was precisely when there was not much happening in class that she remembered to try and notice.

However, these three lecturers stated that they reflected on the lecture afterwards, with two specifically stating that this is something they would do on the walk back to their offices immediately after class. Thus if there was an incident of note to write about, they recalled it easily immediately after the class.

The fact that I consciously looked for something of note to write about after most lectures, meant that things I would normally have just 'ordinary-noticed', I then 'marked' and then if I went on to write about them, or 'record' them, meant that they really were to the forefront of my mind throughout the semester. (Lecturer B)

Indeed, some of the lecturers did note success at noticing in the second semester of the academic year. While this could obviously be explained by having already engaged with the Discipline of Noticing for a semester, the lecturers also conjectured that there were conditions that may be more conducive to noticing than others. In particular, success at noticing was reported when the lecturer had a small class and/or was very familiar with the students in the class.

The regularity with which I met with this group of students (seven times each fortnight) and the resulting regular practice of reflecting and writing accounts helped me to develop an ability to notice 'in the moment'. (Lecturer E)

In the second semester, I found it a bit easier to remember to notice during class. This might be because I was more familiar with the discipline, or maybe the fact that I had much smaller classes helped. (Lecturer D)

\section{Discussion}

Although the five lecturers involved in this study teach mathematics, and indeed, Mason is an eminent researcher in mathematics education, the Discipline of Noticing is not aimed specifically at mathematics teachers. Mason (2002) promotes it to teachers who wish to improve their practice, broadly defining a teacher as 'anyone working with others in some caring or supportive capacity which draws upon the exercise of professional expertise' (1). To the best of our knowledge, this is the first study to explore the use of the Discipline of Noticing as a professional development tool for teachers in higher education. In this section, we discuss the implications of this study for those teaching in higher education that may wish to engage in the Discipline of Noticing as a means of examining and improving practice. 
As noted earlier, Mason (2002) asserts that the Discipline of Noticing is aimed at people working within a supportive group. He notes (144):

Real change also requires the support of a compatible group of people whose presence can sustain individuals through difficult patches, and who provide both a sounding board and a source of challenge for observations, conjectures and theories.

Our results strongly support Mason's assertion and highlight specific benefits of engaging in the Discipline of Noticing as a group. The importance for teachers in higher education of reflecting on practice within a group setting has also been emphasised by others. For example, Bell, Mladenovic, and Segara (2010) contend that sharing and discussing experiences (a social model of reflection) is particularly effective for academic development, while Pereira (1999) also emphasises the need for collaborative reflection. The group aspect of this project seemed to be crucial to its success in another way in that the group dynamic often provided members with the self-discipline that they needed to persevere.

We noted earlier that most of the mathematics lecturers in the study have engaged in mathematics education research. This necessarily has an effect on the way they view and interpret some of the incidents described in their accounts. A study in New Zealand investigating effective professional development processes for university-level mathematics lecturers also highlighted the essential role that a supportive community of practice has to play in enabling reflection and the benefits of this community being 'mixed' (Hannah, Stewart, and Thomas 2011; Paterson, Thomas, and Taylor 2011). We believe that an education perspective, even if it is not subject specific, can be beneficial in enabling reflection on practice.

To summarise, we make the following two recommendations to anyone in higher education wishing to engage in the Discipline of Noticing - do so as part of a group and as a professional development process, the effectiveness of engaging with the Discipline of Noticing could be enhanced if an education perspective can be provided by one or more members of this group.

The study also highlights the benefits, and challenges, teachers might expect from engaging with the discipline. For example, the benefits of writing brief-but-vivid accounts and of perusing a collection of accounts were described. Some of the lecturers were able to identify themes in their own and others' accounts and to identify areas of their own practice on which they would like to improve. The act of writing an account often gave the author a new perspective on incidents in their classrooms. Furthermore, sharing the accounts allowed the group members insight into others' practice and group discussions gave opportunities for identifying different methods of dealing with situations in the future. Indeed, Ryan $(2013,3)$ explains that while reflection has been variously defined from different perspectives and disciplines, at a broad level, there are generally two key elements: '(1) making sense of experience in relation to self, others and contextual conditions; and importantly, (2) reimagining and/or planning future experiences'.

We also caution teachers in higher education engaging with the Discipline of Noticing not to expect too much too soon. We suggest that systematic engagement over a long period is necessary before one can see results. In this study, the lecturers reported difficulties with noticing in-the-moment, especially in the first semester. We suggest that they had unrealistic expectations. Two spoke specifically of how they failed to notice inthe-moment, but generally reflected on incidents on the way back from the lecture to their 
offices. Rather than view this as a failure on their part, we believe this to be an extremely useful first step in learning the discipline. Mason $(2002,39)$ writes that 'Incidents which stay in memory are usually ones in which we have considerable emotional or intellectual commitment'. We believe that recalling incidents immediately after a lecture is a useful practice to engage in for those who wish to graduate to noticing in-the-moment, for as Mason (75) observes: 'Noticing something retrospectively is how most sensitivities begin'.

To conclude, we return to the five mathematics lecturers in this study and examine their next steps in relation to the Discipline of Noticing. As mentioned earlier, Mason (2002) summarises the processes involved under four headings: systematic reflection, recognising, preparing and noticing, and validating with others. The lecturers' reflections mainly relate to the systematic reflection process - the writing, and using, of accounts and the examination of a collection of accounts to identify emerging themes. We suggest that this is because this is the process they had engaged in most over the year. Significantly though, Lecturers B, D and E had identified themes in their accounts that they now wanted to address. We believe that the lecturers are now at the point where they can engage productively with the 'recognising' and 'preparing and noticing' stages of the discipline. In relation to the 'validating with others' stage, each lecturer presented a taskexercise to the group for discussion at the end of the academic year. At this stage, it became apparent that two common themes were emerging from the accounts (namely, promoting student engagement and gauging student understanding), and it was decided to write task exercises on these and to present them to groups of mathematicians at seminars in the coming year. In this way, we hope to receive feedback on the task exercises and more importantly, receive others' perspectives on dealing with these two issues. We believe that in addition to improving the practice of the five lecturers involved, the results of this work have the potential to contribute to the further understanding of mathematicians' classroom practices, an area that is not well researched to date (Speer, Smith III, and Horvath 2010).

\section{References}

Bell, A., R. Mladenovic, and R. Segara. 2010. "Supporting the Reflective Practice of Tutors: What Do Tutors Reflect On?" Teaching in Higher Education 15 (1): 57-70. doi:10.1080/135625 10903488139.

Breen, S., A. McCluskey, M. Meehan, J. O'Donovan, and A. O'Shea. 2011. "Reflection on Practice in Practice: The Discipline of Noticing." Proceedings of the British Society for Research into Learning Mathematics 31 (3): 7-12.

Dewey, J. 1916. Democracy and Education. New York: Macmillan.

Hannah, J., S. Stewart, and M. Thomas. 2011. "Analysing Lecturer Practice: The Role of Orientations and Goals." International Journal of Mathematical Education in Science and Technology 42 (7): 975-984. doi:10.1080/0020739X.2011.610008.

Hatton, N., and D. Smith. 1995. "Reflection in Teacher Education: Towards Definition and Implementation." Teaching and Teacher Education 11 (1): 33-49. doi:10.1016/0742-051X(94) 00012-U.

Jaworski, B., and J. Matthews. 2011. "How We Teach Mathematics: Discourses onlin University Teaching." In Proceedings of the Seventh Congress of the European Society for Research in Mathematics Education, edited by M. Pytlak, T. Rowland, and E. Swoboda, 2022-2032. Poland: University of Rzeszów.

Loughran, J. 2006. "A Response to 'Reflecting on the Self."' Reflective Practice 7 (1): 43-53. doi:10.1080/14623940500489716.

Mason, J. 2002. Researching Your Own Practice: The Discipline of Noticing. London: Routledge Falmer. 
Mason, J. 2011. "Noticing: Roots and Branches." In Mathematics Teacher Noticing: Seeing through Teachers' Eyes, edited by M. Gamoran Sherin, V. R. Jacobs, and R. A. Philipp, 35-50. New York: Routledge.

McAlpine, L., and C. Weston. 2000. "Reflection: Issues Related to Improving Professors' Teaching and Students' Learning." Instructional Science 28 (5): 363-385. doi:10.1023/A:1026583208230.

Moon, J. 2004. A Handbook of Reflective and Experiential Learning: Theory and Practice. London: RoutledgeFalmer.

NCTM (National Council of Teachers of Mathematics). 2010. Professional Development Research Brief. Reston, VA: The National Council of Teachers of Mathematics. http://www.nctm.org/ uploadedFiles/Research_News_and_Advocacy/Research/Clips_and_Briefs/Research_brief_15Goldsmith(1).pdf.

Paterson, J., M. Thomas, and S. Taylor. 2011. "Decisions, Decisions, Decisions: What Determines the Path Taken in Lectures?" International Journal of Mathematical Education in Science and Technology 42 (7): 985-995. doi:10.1080/0020739X.2011.611912.

Pereira, M. A. 1999. "My Reflective Practice as Research." Teaching in Higher Education 4 (3): 339-354. doi:10.1080/1356251990040303.

Ryan, M. 2013. "The Pedagogical Balancing Act: Teaching Reflection in Higher Education. Teaching in Higher Education 18 (2): 144-155. http://dx.doi.org/10.1080/13562517.2012.694104.

Schön, D. A. 1983. The Reflective Practitioner: How Professionals Think in Action. London: Temple Smith.

Schön, D. A. 1987. Educating the Reflective Practitioner. London: Jossey-Bass.

Sherin, M. G., V. R. Jacobs, and R. A. Philipp. 2011. "Situating the Study of Teacher Noticing." In Mathematics Teacher Noticing: Seeing through Teachers' Eyes, edited by M. G. Sherin, V. R. Jacobs, and R. A. Philipp, 3-13. New York: Routledge.

Speer, N. M., J. P. Smith III, and A. Horvath. 2010. "Collegiate Mathematics Teaching: An Unexamined Practice.” The Journal of Mathematical Behavior 29 (2): 99-114. doi:10.1016/j. jmathb.2010.02.001.

Strauss, A., and J. Corbin. 1998. Basics of Qualitative Research. 2nd ed. London: SAGE.

van Es, E. A., and M. G. Sherin. 2002. "Learning to Notice: Scaffolding New Teachers' Interpretations of Classroom Interactions." Journal of Technology and Teacher Education 10: 571-597. 